\title{
Erva, bovino selvagem, tamareira e cedro: ecoespiritualidade no Salmo 92
}

\author{
Herb, wild bovine, date palm and cedar: \\ ecospirituality in Psalm 92
}

Matthias Grenzer

\section{Resumo}

O Salmo 92 acolhe imagens de flora e fauna a fim de, a partir delas, favorecer uma reflexão teológico-espiritual sobre realidades que, de forma conflitante, atingem as convivências entre os seres humanos. Nesse sentido, a oração bíblica em questão menciona a erva comparando-a com os perversos, enquanto reflete sobre o justo como quem se torna semelhante à tamareira e ao cedro. Sua própria fronte, porém, o salmista compara com a de um bovino selvagem. A pesquisa aqui apresentada dedica-se ao estudo desses vegetais e do animal poeticamente mencionados no Salmo 92. Assim será possível descrever o quanto essa oração bíblica promove determinada ecoespiritualidade. Imagina-se, pois, que as pessoas poderão compreender melhor a si mesmas e as convivências entre si quando, em suas reflexões, envolverem a natureza com um olhar qualificado. Afinal, semelhantemente à história, fauna e flora parecem guardar, de forma mística, a capacidade de transmitir uma lição de vida ao ser humano, sendo que tal lição revela a palavra de Deus e uma sabedoria específica nela contida. Por sua vez, no que se refere à justiça, fica claro o quanto as dimensões teológicas e socioambientais precisam ser pensadas conjuntamente.

Palavras-chave: Salmos. Ecoespiritualidade. Flora. Fauna. 


\begin{abstract}
Psalm 92 welcomes images of flora and fauna in order to, from them, benefit a theological-spiritual reflection on realities that, in a conflicting way, affect the coexistence between human beings. In this sense, the biblical prayer in question mentions the herb comparing it with the wicked, while reflecting on the just as one who becomes similar to a date palm and cedar. It's own forehead, however, the psalmist compares with the horn of a wild bovine. The research presented here is dedicated to the study of these plants and the animal poetically mentioned in Psalm 92. Thus it will be possible to describe how much this biblical prayer promotes a certain ecospirituality. It is imagined, therefore, that people will be able to better understand themselves and their coexistence when they involve a qualified look at nature in their reflections. After all, similar to history, fauna and flora seem to keep, in a mystical way, the ability to transmit on a life lesson to the human beings, a lesson that reveals the word of God and the specific wisdom contained therein. In turn, when it comes to justice, it is clear how much theological and socio-environmental dimensions need to be thought out together.
\end{abstract}

Keywords: Psalms. Ecospirituality. Flora. Fauna.

\title{
Introdução
}

O orante ou salmista, figura inerente aos Salmos, contempla, em diversos momentos, a fauna e a flora. Ao acolher "a possibilidade provinda do idioma de ilustrar sua afirmação", utiliza diversos vegetais e animais como metáforas e comparações. ${ }^{1}$ Esse fenômeno não é constante nos Salmos; no entanto, a presença multiplicada de árvores, vegetais baixos e animais chama a atenção do ouvinte-leitor dessas orações bíblicas. Por isso, antes de o estudo aqui apresentado se dedicar ao Salmo 92, a título de aproximação ao tema da ecoespiritualidade será oferecida aqui uma lista possivelmente completa dos vegetais e animais no livro dos Salmos.

${ }^{1}$ SEYBOLD, K., Poetik der Psalmen, p. 193. 


\section{Vegetais lenhosos, vegetais herbáceos e animais nos Salmos}

O substantivo hebraico comumente traduzido como "árvore" (עي) aparece seis vezes nos Salmos (S1 1,3; 74,5; 96,12; 104,16; 105,33; 148,9). Além disso, o ouvinte-leitor encontra ali árvores específicas. O "cedro" (אֶ:) é seis vezes mencionado (S1 29,52x; 80,11;92,13; 104,16; 148,9) e uma só

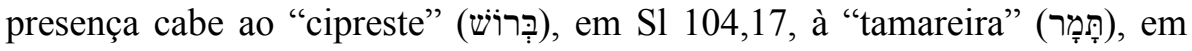

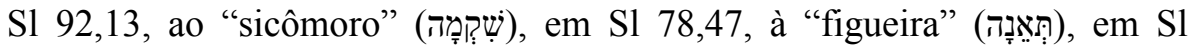
104,33, ao "salgueiro" (עָרָרָה), em S1 137,2 e, aparentemente, ao "carvalho"

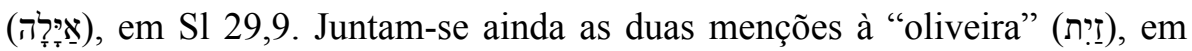
S1 52,10; 128,3, e as cinco da "videira" ()ֶֶֶ), em S1 78,47; 80,9.15; 105,33; 128,3. Vale aludir também aos arbustos da "giesta" (רֶֶֶ), em S1 120,4, e ao "espinheiro" (אָָָָ), em S1 58,10. Ademais, o ouvinte-leitor dos Salmos há de pensar nas árvores, quando é citado, sete vezes, o "bosque" (יעַ), em S1 29,9; 50,10;80,14;83,15;96,12;104,20; 132,6, e, uma vez, a "vinha" (יכרך), em S1 107,37, por tratar-se de espaços que nascem de um conjunto de vegetais lenhosos. Do mesmo modo, pressupõe-se essa presença quando há menção à

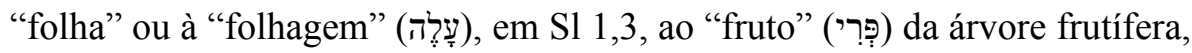

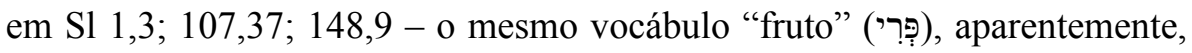
indica a produção dos vegetais baixos em S1 72,16; 105,35, ou da "terra fértil"

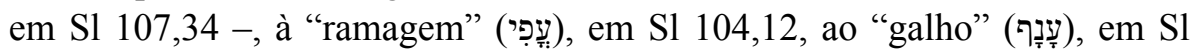

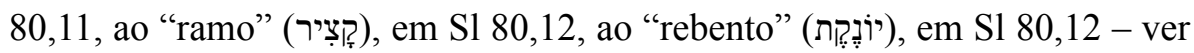

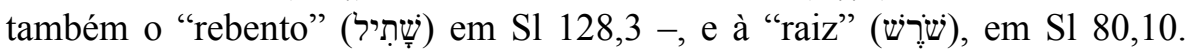

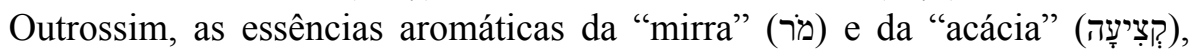
ambas citadas em S1 45,9, trazem à memória do ouvinte-leitor dos Salmos as árvores correspondentes. O mesmo vale para a base do "perfume" e/ou para o alimento do "óleo" ou "azeite" (שֶֶׁ)), em S1 23,5; 45,8; 55,22; 89,21; 92,11; 104,$15 ; 109,18.24 ; 133,2 ; 141,5$, assim como para as bebidas do "mosto"

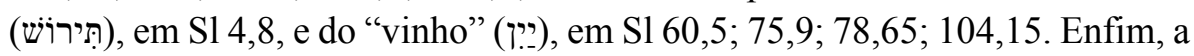
menção a treze espécies de árvores ou arbustos, assim como os vocábulos mais genéricos ligados aos vegetais lenhosos ou aos espaços onde eles existem, deixa a impressão de que o salmista procura o contato com a natureza para qualificar seu diálogo com Deus e sua reflexão sobre o ser humano.

Essa impressão se intensifica ao se identificar os vegetais menores nos Salmos. Um primeiro grupo é formado por três palavras hebraicas: a "erva" (עָשָׁ), em S1 72,16; 92,8; 102,5.12; 104,14; 105,35; 106,20, a "erva nova" ou "relva verde" (חְִִָיר), em S1 37,2; 90,5; 
103,$15 ; 104,14 ; 129,6 ; 147,8$. Ao se tratar do alimento principal do gado grande e pequeno, entram no horizonte também os espaços em que se encontra tal

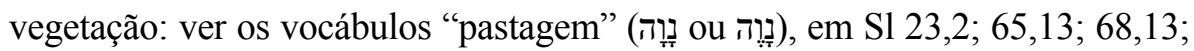
74,20; 79,7; 83,13, "prado" (רֵַ), em S1 37,20; 65,14, e "pasto" (מְרְִִית), em S1 74,1; 79,13; 95,7; 100,3. Nesse contexto, cabe ainda lembrar o vegetal do "caniço" (קָנָָּ), em Sl 68,31. Um segundo grupo de vocábulos ligados ao campo semântico dos vegetais menores gira em torno da produção de grãos, fonte

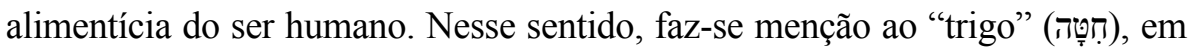

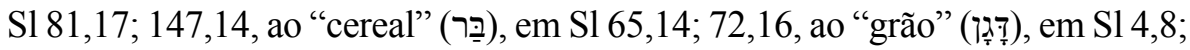

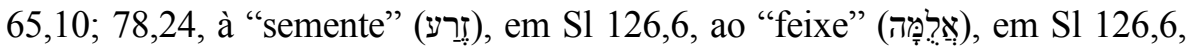
ao "debulho" (מק), em S1 1,4; 35,5, à "palha" (קָׁ), em S1 83,14, e aos trabalhos de "plantar" (נטע), em S1 80,9.16; 104,16; 107,37, "arar" (חרשץ), em S1 129,3, "semear" (זרע), em S1 97,11; 107,37; 126,5, "ceifar" (קצר), em S1 126,5; 129,7,

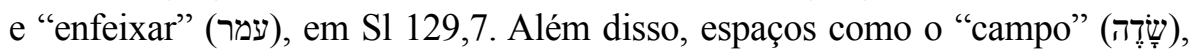

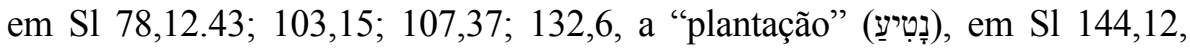

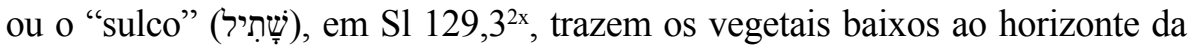
reflexão. $\mathrm{O}$ mesmo vale para os alimentos produzidos pelos vegetais baixos, embora o livro dos Salmos mencione apenas o "pão" (לְֶ), em Sl 14,4; 37,25; 41,$10 ; 42,4 ; 53,5 ; 78,20.25 ; 80,6 ; 102,10 ; 104,14.15 ; 105,16.40 ; 127,2 ; 132,15$; 136,$25 ; 146,7 ; 147,9$. No mais, os Salmos apresentam as plantas baixas do "aloés" (אָהָלוֹת), em S1 45,9, do "hissopo" (אָזוֹב), em S1 51,9, do "junco" (סוּר), em S1 106,7.9.22; 136,13.15, do "cardo" (אוץץ), em S1 118,12, e, como termo mais coletivo ou genérico, a "flor" (צִ), em S1 103,15. Enfim, as menções a sete vegetais específicos, o olhar sobre a "flor do campo" $(\mathrm{S} 1$ 103,15) e a presença de um conjunto de palavras ligadas às plantas baixas reforçam a impressão de que o salmista, como as pessoas nas mais diversas épocas, convive com a natureza. ${ }^{2}$

A questão ecológica nos Salmos, no entanto, precisa ser estendida ainda à presença dos animais, os quais, por respirarem, são compreendidos como seres vivos, uma vez que, na antiguidade, ainda não se conhecia o processo de respiração das plantas. A lista dos animais e de suas múltiplas menções nos Salmos é longa. ${ }^{3}$

\footnotetext{
${ }^{2}$ Para o estudo dos vegetais bíblicos, ver ZOHARY, M., Plants of the Bible; HÄUSL, M., Vom Garten Eden bis zu Salomos Weinberg; DUKE, J. A., Duke's Handbook of Medicinal Plants of the Bible; TAL, A., All the Trees of the Forest; COMMITTEE ON TRANSLATIONS OD THE UNITED BIBLE SOCIETIES, Fauna and Flora of the Bible; MUSSELMAN, L. J., A Dictionary of Bible Plants.

${ }^{3}$ Segue-se aqui, no que se refere à classificação dos animais em categorias, a proposta de DEYSEL, L. C. F., Animal names and categorisation in the Hebrew Bible.
} 
Primeiramente, apresenta-se a categoria dos animais terrestres, começando com subgrupo dos animais domésticos: o "gado pequeno" (צאן), em S1 44,12.23; 49,15; 65,14; 74,1; 77,21; 78,52.70; 79,13; 80,2; 95,7; 100,3; 107,$41 ; 114,4.6 ; 144,13$ - ver também o "gado pequeno" (צִּנָ) em S1 8,8

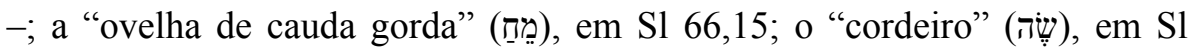

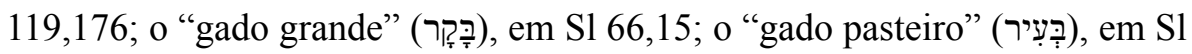
78,48; o "gado manso" (בָּרוּר), em S1 144,14; o "animal" ou o "gado" como

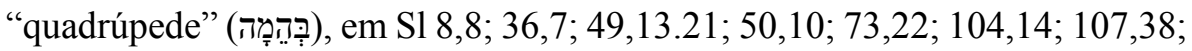
135,8; 147,9; 148,10; o "touro" (שiוֹ), em S1 69,32; 106,20; o "touro ensinado"

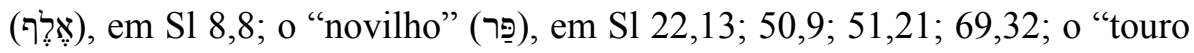

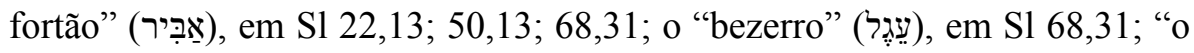

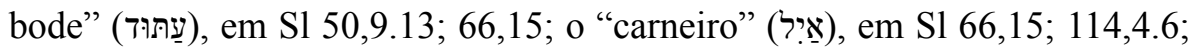

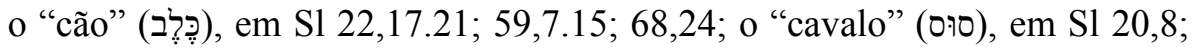
32,9; 33,17; 76,7; 147,10; o "burro" (פָרָ), em S1 32,9.

Outro subgrupo de animais terrestres é formado pelos animais selvagens,

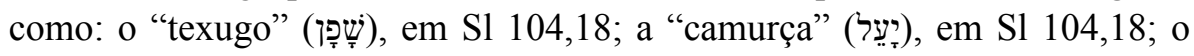

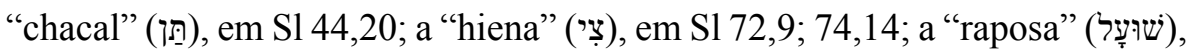

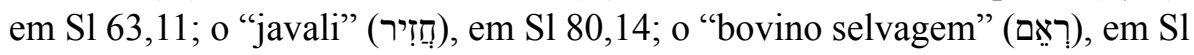

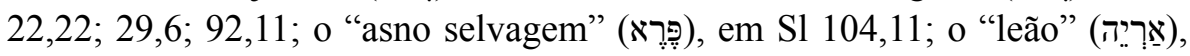
em S1 7,3; 10,9; 17,12; 22,14.22; o "filhote do leão" (שַָָׁ), em S1 91,13; o

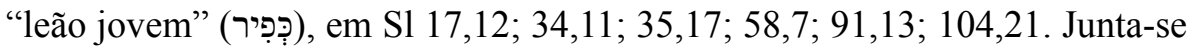
a isso o "bicho do campo" (ז̣), em S1 50,11; 80,14, além de falar-se, de forma genérica, do "animal" ou do "ser vivo do bosque", da "fera" e/ou do "animal da terra" ou "do campo" (חָ), em S1 50,10; 68,11.31; 74,192x; 78,50; 79,2; $104,11.20 .25 ; 143,3 ; 148,10$, sendo que o termo "animal do campo" pode se referir também ao grupo dos animais domésticos.

Uma segunda categoria nasce dos animais rastejadores. Nesse sentido,

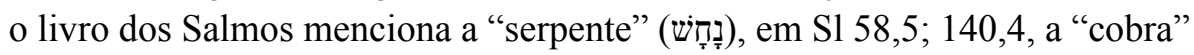

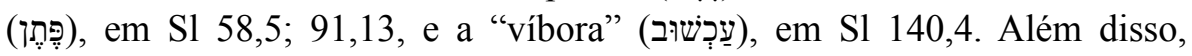

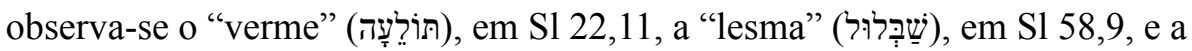

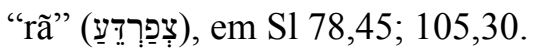

A terceira categoria é formada pelos animais voadores, igualmente presentes no livro dos Salmos. De forma genérica, encontra-se o "pássaro"

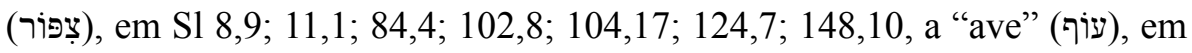

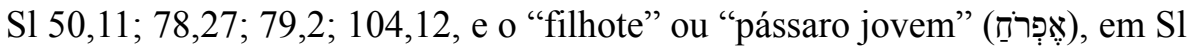
84,4. Como espécie, menciona-se a "andorinha" (רָּרוֹ), em S1 84,4, o "abutre"

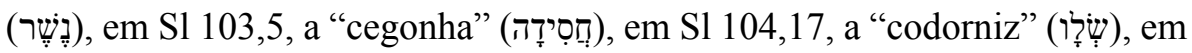




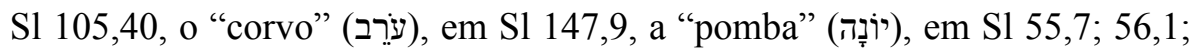
68,14, e a "rolinha" (תוֹר), em S1 74,19.4 Também entram nessa lista os insetos voadores, como a "mosca" (עָרב), em S1 78,45; 105,31, o "mosquito" (כָּב ), em S1 105,31, o "gafanhoto" (ארֵֶֶּ), em S1 78,46; 105,34; 109,23, a "locusta"

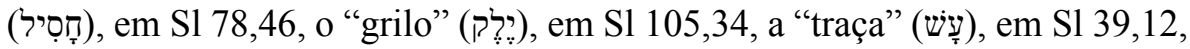

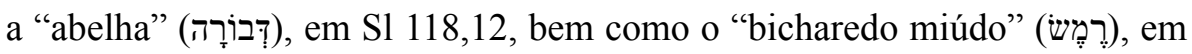
S1 104,25; 148,10.

A quarta categoria acolhe os animais nadadores. Nesse sentido, encontra-

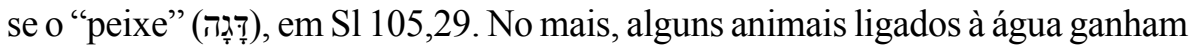
presença como representantes de monstros míticos: veja-se a proximidade entre

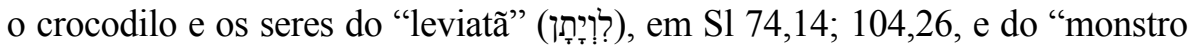

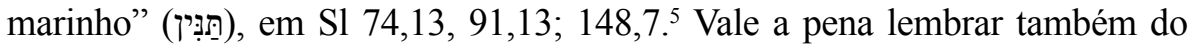
"Raab" (רָהַ) como representante do Egito e do mar em S1 87,4; 89,11.

Assim como no caso dos vegetais herbáceos e lenhosos, certos vocábulos trabalhados nos Salmos trazem à memória do ouvinte-leitor os animais. Ora se trata de partes específicas do animal, como a "asa" (כָָָָ), em Sl 17,8; 18,11; 36,$8 ; 57,2 ; 61,5 ; 63,8 ; 68,14 ; 78,27 ; 91,4 ; 104,3 ; 139,9 ; 148,10$, a "asa" e/

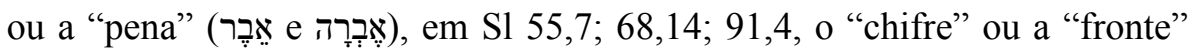

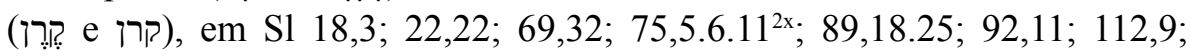
118,$27 ; 132,17 ; 148,14$, ou o "casco fendido" (פרס), em S1 69,32; ora se visa a conjuntos de animais - ver o "rebanho" (עָדָר), em S1 78,52, e a "manada" (מִקְנְנָ), em S1 78,48 -, ou a um lugar em que animais se fazem presentes, como

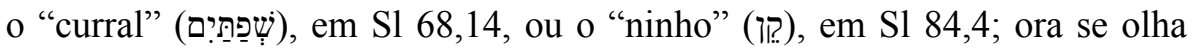
para determinados materiais obtidos a partir dos animais, como o "marfim" (שָׁ), em S1 45,9, e o couro do "odre" (נאד), em S1 56,9; 119,83; ora se trata de

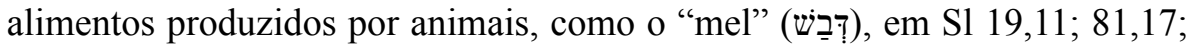

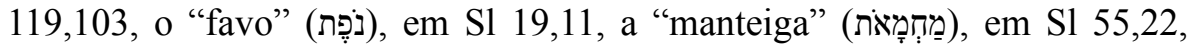

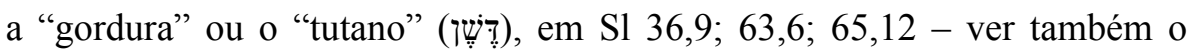
vocábulo traduzível como "gordura" (חילְ) em Sl 17,10; 63,6; 73,7; 119,70, enquanto a mesma palavra indica "o melhor" ou a "flor do trigo" em Sl 81,17;

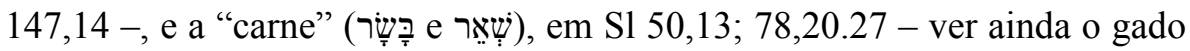
pequeno como "alimento" (צמאָכָרָ) em S1 44,12. Eventualmente, os vocábulos "provisão" (צִיד), em S1 132,15, e "mantimento" (צִיזָה), em S1 78,25, se referem

${ }^{4}$ Em relação ao pássaro ora compreendido como "abutre" ora como "águia" (ฏְֶֶֶ), ver GRENZER, M.; BREY, P., Águia ou abutre? (Ex 19,4).

${ }^{5}$ No que se refere ao crocodilo como representante do leviatã e do monstro marinho, ver KEEL, O., Jahwes Entgegnung an Ijob, p. 141-156. 
à caça. Finalmente, sejam lembrados outros três vocábulos ligados ao mundo

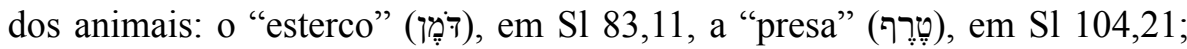
124,6, e a "rede" (חפ) do caçador, em S1 91,3; 124,72x.

Resumindo, ao contemplar esse campo semântico ligado aos animais é possível ter uma primeira impressão sobre o espaço que também a fauna ocupa no livro dos Salmos. O salmista acolhe, pois, cinquenta e quatro animais diferentes em suas orações, além de juntar um vocabulário que, de forma indireta, traz os animais à memória do ouvinte-leitor. No entanto, não se faz jus aos Salmos impressionar-se apenas com a quantidade dos elementos de fauna e flora presentes nessas orações bíblicas. Somente ao perceber a profundidade da reflexão teológica veiculada pelas metáforas e comparações acolhedoras de vegetais lenhosos, vegetais herbáceos e animais será possível descobrir que existe uma ecoespiritualidade nos Salmos. Para verificar isso in loco, visite-se agora o Salmo 92.

\section{A estrutura poética do Salmo 92}

O Salmo 92 é um texto artisticamente configurado. Trata-se de poesia lírica. Por isso, observem-se aqui alguns detalhes em relação à forma do poema. Eis uma tradução mais literal e segmentada:

v.1 Salmo. Canto para o dia do sábado.

v. 2a É bom agradecer ao SENHOR

v. $2 \mathrm{~b}$ e salmodiar teu nome, ó Altíssimo,

v. 3a anunciar tua lealdade de manhã

v. $3 \mathrm{~b}$ e tua fidelidade durante as noites,

v. 4a com um instrumento de dez cordas e com uma lira,

v. $4 \mathrm{~b}$ com a dedilhação numa cítara.

v. 5a Porque me alegraste com teu fazer, SENHOR,

v. $5 b$ jubilo com as obras de tuas mãos.

v. $6 \mathrm{a}$ Como são grandes tuas obras, SENHOR,

v. $6 \mathrm{~b}$ teus projetos são muito profundos!

v. $7 \mathrm{a} O$ homem estúpido não o sabe

v. $7 \mathrm{~b}$ e o insensato não entende isso.

v. $8 \mathrm{a}$ Ao terem florescido os perversos como erva, 
v. $8 \mathrm{~b}$ todos os malfeitores brotaram,

v. $8 \mathrm{c}$ a fim de serem suprimidos para sempre.

v. 9a Tu, porém, és eternamente elevado, ó SENHOR.

v. 10a Porque eis teus inimigos, SENHOR:

v. $10 \mathrm{~b}$ eis que teus inimigos perecerão,

v. 10c todos os malfeitores se dispersarão.

v. 11a Elevaste minha fronte como (a) de um bovino selvagem:

v. 11b fiquei umedecido com perfume exuberante.

v. 12a Meu olho contempla os que me espreitam,

v. $12 \mathrm{~b}$ meus ouvidos escutam malvados entre os que se erguem contra mim.

v. 13a O justo florescerá como a tamareira,

v. 13b crescerá como um cedro no Líbano.

v. 14a Plantados na casa do SENHOR,

v. 14b florescerão nos átrios de nosso Deus.

v. 15a Ainda prosperarão de cabelo grisalho,

v. 15 b serão seivosos e exuberantes,

v. 16a para anunciar: "Realmente, o SENHOR é reto.

v. 16b É meu rochedo e nele não há iniquidade".

A oração apresenta um discurso individual. Após inicialmente prevalecer um discurso impessoal (v. 2-4), o salmista adota, na parte central do poema (v. 5-12), a primeira pessoa do singular. Ora o verbo é conjugado nessa forma (v. 5b.11b), ora os sufixos pronominais insistem em tal perspectiva (v. 5a.11a.12a $\mathrm{a}^{2 \mathrm{x}}$.b.c.16b). No entanto, em um só momento, os sufixos pronominais insistentes na primeira pessoa do singular cedem espaço à visão comunitária, sendo que, no v. 14b, o salmista, ao olhar para o templo, diz "nosso Deus", fazendo uso do sufixo pronominal da primeira pessoa do plural.

O eu do salmista, por sua vez, dialoga com o tu, que é o Senhor, Deus de Israel. Nesse sentido, observa-se que o tetragrama ocorre sete vezes no S1 92 (v. 2a.5a.6a.9a.10a.14a.16a), sendo "o número sete amplamente usado como dispositivo estilístico", inclusive para tornar transparente a semana de criação (Gn 1,1-2,4a) e o sétimo dia dela, que é "o dia do sábado" (v. 1). ${ }^{6}$ Todas as ocorrências na parte central do Salmo (v. 5-12)

${ }^{6}$ SARNA, N. M., The Psalm for the Sabbath Day (Ps 92), p. 167. 
trazem o nome de Deus como vocativo, ao contrário do que se percebe na primeira e terceira parte da oração poética (v. 2-4.13-16). Além disso, quatro epitetos, somente na primeira e última parte, acompanham o tetragrama: o "nome" (v. 2b), o "Altíssimo" (v. 2b), "Deus" (v. 14b) e o "rochedo" (v. 16b). Também se ouve ou lê, justamente nessas duas partes que molduram o Salmo, sobre quatro qualidades éticas atribuídas ao Senhor: a "lealdade" (v. 3a), a "fidelidade" (v. 3b), a "retidão" (v. 16a) e a "ausência de iniquidade" (v. 16b). No mais, dez sufixos pronominais se referem ao Senhor (v. 2b.3a.b.5a.b.6a.b.10a.b.16b), além de este último precisar ser pensado como sujeito no caso de dois verbos na segunda pessoa do singular (v. 5a.11a). Ganha ainda destaque a frase nominal no centro do S1 92, em que o salmista se dirige a seu Deus usando, no início, o pronome pessoal absoluto da segunda pessoa do singular e, no final, o nome dele: "Tu, porém, és eternamente elevado, ó SenHor" (v. 9a). Aliás, trata-se do "centro semântico, retórico e estrutural do Salmo", uma vez que quinze linhas com cinquenta e duas palavras antecedem o que se encontra no v. 9a, e quinze linhas com cinquenta e duas palavras seguem tal verseto. ${ }^{7}$ No mais, juntando as quatro palavras do verseto central (v. 9a) e as quatro palavras do título (v. 1), percebe-se que o S1 92 é formado pelo simbólico número de sessenta palavras. Finalmente, observe-se ainda que o salmista, diferentemente de seu diálogo direto com Deus em praticamente toda a oração dele, discursa na primeira linha sobre o Senhor (v. 2b). A isso corresponde, no final do poema oracional, o discurso dos retos sobre o Senhor, relatado (v. 16a) e citado (v. 16b) pelo salmista. Assim, ouve-se ou lê-se o único sufixo pronominal da terceira pessoa singular (v. 16b), que, como os outros nove da segunda pessoa singular (v. 2b.3a.b.5a.b.6a.b.10a.b), se refere ao Senhor. Quer dizer, no início e no final do S1 92, o diálogo com Deus se transforma em discurso sobre Deus, ou seja, em "anúncio" (v. 3a.16a), sendo que a presença dessa raiz verbal (נגד) nas extremidades da oração reforça a impressão de existir uma moldura e/ou inclusão. Todavia, essa mudança de perspectiva, com um salmista que ora se dirige a Deus, ora à comunidade para lhe falar sobre Deus, é uma característica dos Salmos. ${ }^{8}$

No mais, o salmista, após ter iniciado seu diálogo com o Senhor na estrofe

\footnotetext{
${ }^{7}$ TUCKER, W. D., The Ordered World of Psalm 92, p. 362.

${ }^{8}$ Ver o emprego desse elemento estilístico de forma característica no Salmo 23 (GRENZER, M., Pastoreio e hospitalidade do Senhor (S1 23)).
} 
inicial (v. 2-4), preocupa-se com dois grupos. Na estrofe central (v. 5-12), visa primeiramente a um conjunto de pessoas opositoras a ele e a Deus. Eis a lista de expressões usadas por quem reza: "homem estúpido" (v. 7a), "insensato" (v. 7b), "perversos" (v. 8a), "malfeitores" (v. 8b.10c), "inimigos" do Senhor (v. 10a.b), "espreitadores" (v. 12a) e "malvados" que "se erguem" contra o outro (v. 12b). Na terceira e última estrofe (v. 13-17), o salmista visa, no entanto, ao "justo" (v. 13a), ora como indivíduo (v. 13a-b.16b), ora como grupo (v. 14-15). Ao terminar sua oração, as palavras do salmista parecem até confundir-se com as palavras dos justos (v. 16). Todavia, para caracterizar o comportamento e o destino de ambos os grupos - dos justos e dos malfeitores perversos -, o salmista envolve, de forma extensa, comparações e metáforas ligadas à fauna e à flora. Sejam estudados agora tais símiles, sendo que eles, tanto em vista da configuração poética como em relação à reflexão teológico-espiritual do S1 92, exercem uma função importante. Aliás, no nível da linguagem, as imagens oriundas da vida animal e dos vegetais ganham realce a partir do quádruplo uso da mesma conjunção comparativa (כ̣ ou iุ

\section{Como a erva}

Quando realidades caóticas atingem a pessoa, é difícil encontrar palavras para descrever o que acontece. Isso vale também para o salmista no S1 92. Admirador dos "feitos" (v. 5a), das "obras" (v. 5b.6a) e dos "projetos" (v.

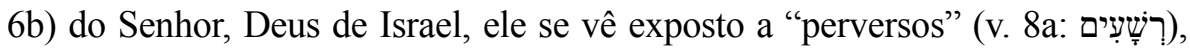

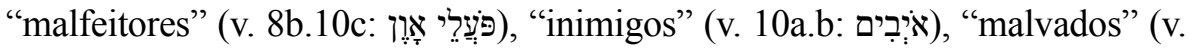

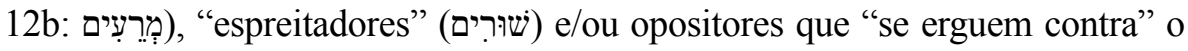

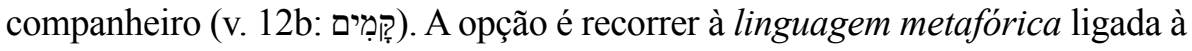
fauna e à flora. De forma surpreendente, pois, "o emprego de uma imagem gera ordem numa sequência de acontecimentos percebidos como caóticos", no sentido de "a força das imagens provindas da natureza se encontrar na adequabilidade evidente delas", justamente por se tratar de "símbolos arquétipos". 9

Nesse sentido, a primeira imagem introduzida no Sl 92 por meio da

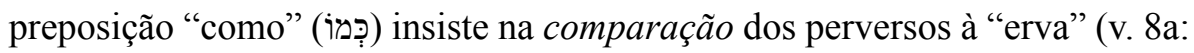
עֵنֶֶ). O vegetal em questão, trinta e três vezes mencionada na Bíblia Hebraica - ver Gn 1,11.12.29.30; 2,5; 3,18; 9,3; Ex 9,22.25; 10,12.152x; Dt 11,15; 29,22; 32,2; 2Rs 19,26; Jó 5,25; S1 72,16; 92,8; 102,5.12; 104,14; 105,35; 106,20; Pr

${ }_{9}^{9}$ STICHER, C., "Die Gottlosen gedeihen wie Gras", p. 252-253. 
19,12; 27,25; Is 37,27; 42,15; Jr 12,4; 14,6; Am 7,2; Mq 5,6; Zc 10,1 -, indica gramíneas, ou seja, vegetais herbáceos, tratando-se ora de plantas selvagens, ora de plantas cultivadas pelo ser humano (S1 104,14). A Bíblia contempla as "ervas", sobretudo, como alimento, seja para os animais selvagens e domésticos (Dt 11,15; Jr 14,6; Sl 106,20), seja para o ser humano (Gn 3,18; Zc 10,1; S1 104,14). ${ }^{10}$ Nesse sentido, relva e feno são ervas, mas legumes, verduras e cereais também o são. No mais, de forma característica, parte-se da ideia de que as ervas, em princípio, "germinam na época chuvosa e ressecam no verão" (Gn 2,5). ${ }^{11}$ Ao mesmo tempo, sabe-se que as chuvas torrenciais (Ex 9,22.25), o gafanhoto (Ex 10,12.15²x; Am 7,2; Sl 105,34-35), um incêndio (Dt 29,22 ) ou a aridez e secura (Is 42,15 ; Jr 12,4) podem destruir "toda erva". Lembra-se ainda que, juntamente com palavra erva (يָָָׁב), outros substantivos formam um campo semântico com sobreposições parciais. Assim, também abrangendo coletivamente diversas espécies de plantas, existem os vocábulos

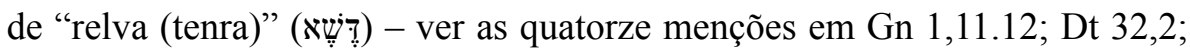
2Sm 23,4; 2Rs 19,26; Jó 6,5; 38,27; S1 23,2; 37,2; Pr 27,25; Is 15,6; 37,27; 66,14; Jr 14,5 -, de "capim" ou "feno" (חָצִיר) - ver as vinte e uma presenças em 1Rs 18,5; 2Rs 19,26; Jó 8,12; 40,15; S1 37,2; 90,5; 103,15; 104,14; 129,6; 147,$8 ; \operatorname{Pr} 27,25 ;$ Is 15,$6 ; 34,13 ; 35,7 ; 37,27 ; 40,6.7^{2 x} .8 ; 44,4 ; 51,12-$, de "algo verde" (יְרק) - ver as oito ocorrências em Gn 1,30; 9,3; Ex 10,15; Nm 22,4; 2Rs 19,26; S1 37,2; Is 15,6; 37,27 - e/ou de “verdura" (ירָז) - ver Dt 11,10; 1Rs 21,2; Pr 15,17. Em vista disso, Gn 1,11-12 parece imaginar que toda

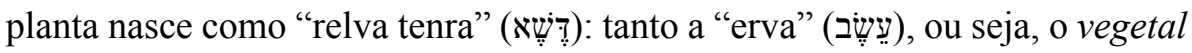
herbáceo, como a "árvore" (עָע), o vegetal lenhoso. E, segundo Gn 1,29-30,

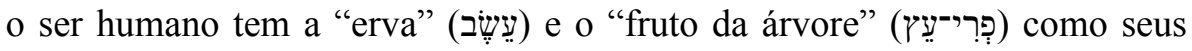
alimentos - assim como a "verdura" (יָרָָ) da "horta" (Dt 11,10; 1Rs 21,2; Pr

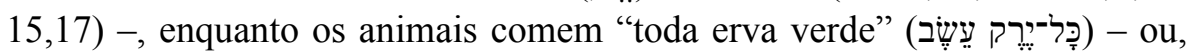

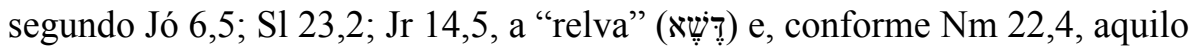
que é "verde" (יר?:), respectivamente, de acordo com 1Rs 18,5; Is 34,13; S1

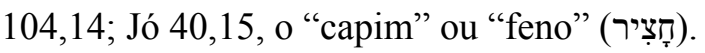

Diante dessa experiência com a flora, visando-se à "erva" (עָשָׁ), surge

\footnotetext{
${ }^{10}$ Gn 9,3 não imagina "o verde da erva" - no sentido de "erva verde" ou "erva verdejante" como alimento do ser humano, pois, segundo Gn 1,30, trata-se do alimento do animal. Indicase, por sua vez, metaforicamente que haverá "uma existência exuberante de animais como base alimentícia" para o ser humano como, de forma abundante, existe o verde das ervas (BAUMGART, N. C., Die Umkehr des Schöpfergottes, p. 308).

${ }^{11}$ MAIBERGER, P., עָשָׁ'séb, p. 383.
} 
a pergunta sobre o que o S1 92 dá a entender ao referir-se a tal vegetal? É comum na literatura veterotestamentária imaginar que os seres humanos, em geral, são como a "erva do campo" ou a "erva da terra": ver os "habitantes das cidades" em 2Rs 19,26; Is 37,27; S1 72,16, ou os "descendentes" do "homem mortal repreendido por Deus" (Jó 5,17.25). Semelhantemente, S1 90,5; 103,15 descrevem os "filhos do ser humano" ou o "homem mortal" como "capim", assim como, em Is 40,6, "toda a carne" e, em Is 40,7, o "povo" são "capim". Ou seja, visando ao destino, "o homem" é aquele que "morre" e "o filho do ser humano" é quem "é entregue como capim" (Is 51,12). Com isso, realça-se a brevidade da vida. Como, pois, a "erva", o "capim" ou mesmo uma "flor do campo" (Jó 14,2; S1 103,15; Is 40,6.7.8), também "o nascido da mulher" é alguém de "dias breves". No entanto, enquanto um "resseca como a erva" (S1 102,5.12) ou "desaparece como capim", o outro "aparece como relva tenra", sendo que também este logo será "erva colhida" (Pr 27,25). Basta um "orvalho" ou uma "garoa" para fazer a "erva" brotar novamente (Dt 32,2; Mq 5,6; Pr 19,12), sendo que, em relação ao ser humano, essa umidade criadora é comparada à "palavra de Deus" e, por consequência, ao "resto de Jacó" ou ao "rei".

No S1 92, no entanto, a imagem da "erva" é aplicada somente aos "perversos" (v. 8a) e "malfeitores" (v. 8b). No caso, o orante afirma que "perversos floresceram como erva" (v. 8a) e que, assim, "brotaram todos os malfeitores" (v. 8b). No entanto, o destino dos dois seria "a supressão deles", e isso "para sempre" (v. 8c). Cabe, portanto, às pessoas, de modo especial as insistentes na perversidade, aprender da erva a lição da brevidade e, com isso, a sabedoria de que, em princípio, será substituída rapidamente por outra erva. Mais ainda, nasce com isso um contraste irônico em relação aos perversos e malfeitores: a presença deles será curta (v. 8a), mas sua ausência será eterna (v. 8c). Para o justo sofredor, por sua vez, o S1 92 prevê outro destino.

\section{Chifre ou fronte como de um bovino selvagem}

A segunda imagem no S1 92, novamente introduzida pela proposição "como" (כִ̣), traz um animal: o "bovino selvagem" (v. 11a: רְ̣). Mais exatamente, ao "mencionar sua própria experiência de salvação", o orante pensa no chifre do bovino selvagem. ${ }^{12}$ Contudo, para compreender bem a

${ }^{12}$ ZENGER, E., Psalm 92, p. 636. 
formulação no v. 11a, é preciso diferenciar entre os dois elementos. De um lado, o poema traz uma metáfora, quando formula: "Elevaste minha fronte (meu chifre)". Para evitar a acepção pejorativa do vocábulo "chifre" (v. 11a: (קֶרו ) na língua portuguesa, traduz-se aqui como "fronte". De outro lado, o poema investe na ideia da igualdade, semelhança e/ou correspondência, trazendo uma comparação introduzida pela preposição comparativa "igual a" ou "como" (v. 11a: כ̦̣). Mais ainda, a formulação hebraica, de modo retórico, antecipa o elemento da comparação - "Elevaste, igual a um bovino selvagem,

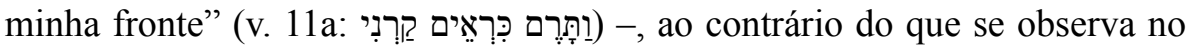
v. 8a. Essa sequência de palavras na frase hebraica, porém, não é mantida em português.

Diversos animais selvagens e domésticos - gado bovino, ovino e caprino - têm chifre. A Bíblia Hebraica menciona os "chifres" do "carneiro" (איִּר), em Gn 22,13; Dn 8,3.6.7.20, do "cabrão" (צִָּּיר), em Dn 8,5.8.21, do "novilho" (רפ), em S1 69,32, e do "bovino selvagem”, em Dt 33,17; S1 22,22. Sabe-se que o chifre, de acordo com seu tamanho, ora serve ao animal como "arma contra um animal selvagem", ora para impor ao membro da mesma espécie, via "linguagem corporal", sua "posição mais alta na hierarquia". ${ }^{13}$ Quanto mais poderio cabe ao animal, mais "eleva o chifre" (v. 11a).

No caso do S1 92, no entanto, se visa a um "chifre como de um bovino selvagem" (v. 11a). Entre os nove vocábulos diferentes para os bovinos na Bíblia Hebraica, dois deles, como designações genéricas, insistem no critério da espécie e/ou do coletivo. De um lado, há o bovino selvagem ou o auroque

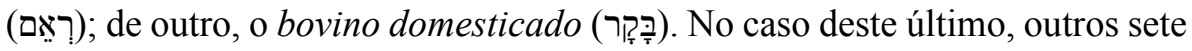
vocábulos insistem em diferenciações adotando o critério do gênero - ver a

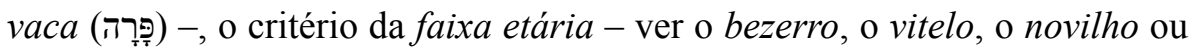

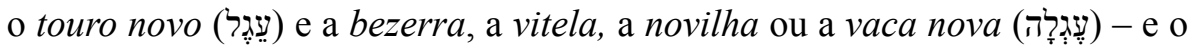
critério da função - ver o touro forte ou valente (אַבְּר), o touro a ser ensinado para a lavoura e a pecuária (אֶלֶ), o touro como animal de pasto e propriedade rural (שוֹ) e o touro usado para o sacrifício (רפ). ${ }^{14}$

O bovino selvagem, por sua vez, nove vezes mencionado na Bíblia

\footnotetext{
${ }^{13}$ RIEDE, P., "Doch Du erhöhtest wie einem Wildstier mein Horn”, p. 210-211.

${ }^{14}$ Acolhe-se aqui o estudo sobre os bovinos no Antigo Testamento de Klaus KOENEN [“... denn wie der Mensch jedes Tier nennt, so soll es heissen” (Gn 2,19), p. 539], lembrando que, "para Israel, não se comprova a existência de touros castrados, mas, segundo Lv 22,24b, se trata até de uma prática proibida". Portanto, a tradução comum de vários dos substantivos acima elencados por boi, em princípio, pode causar uma compreensão equivocada.
} 
Hebraica (Nm 23,22; 24,8; Dt 33,17; Jó 39,9.10; S1 22,22; 29,6; 92,11; Is 34,7 ), impressiona com "uma altura de 1,75-1,85 m, com um comprimento até $3,10 \mathrm{~m}$, com um peso até $1.000 \mathrm{~kg}$ " e, especialmente, com seus "chifres longos,

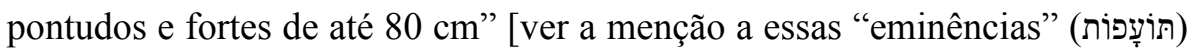
em Nm 23,22; 24,8, ou desses "chifres" (קרְּ) em Dt 33,17; S1 22,22]. ${ }^{15}$ Mais ainda, segundo a literatura bíblica, o bovino selvagem é "sinônimo de vigor e força, e até de soberania e liberdade", sendo que "o homem", em princípio, "não tem poder sobre ele", uma vez que não consegue domesticá-lo (Jó 39,910). ${ }^{16}$ Em contrapartida, em meio aos textos e às imagens iconográficas que visam à caça de animais selvagens, também aparece o bovino selvagem. ${ }^{17}$ Todavia, ao contemplar justamente esse animal selvagem, especialmente seu chifre, o orante no S1 92 afirma a respeito do Senhor, Deus de Israel: "Elevaste minha fronte como (a) de um bovino selvagem" (v. 11a). Quer dizer, "mesmo que muitos animais ameaçassem os humanos e que, por isso, estes últimos os combatessem, isso não impedia de também admirar tais animais", sendo que "inúmeras comparações e metáforas mostram a estreita conexão entre humanos e animais, baseada na observação". ${ }^{18}$ Ou seja, além da flora, também a fauna transmite sua sabedoria, sendo que esta última inclui, centralmente, um conhecimento a respeito de Deus.

Nesse sentido, acolhendo os paralelismos oferecidos pelos escritos bíblicos, é interessante observar como Davi contempla "Deus" como "chifre de sua salvação" (2Sm 22,3; Sl 18,3). ${ }^{19}$ Além disso, de forma repetida, Deus é pensado como quem "eleva" ou "faz brotar a fronte" de alguém, respectivamente como quem "coloca uma fronte" mais resistente em alguém, ou que "a fronte" de alguém "se eleva no Senhor": ver Ana (1Sm 2,1), o ungido de Deus (1Sm 2,10), Sedecias (1Rs 22,11; 2Cr 18,10), o justo (S1 $75,11 ; 112,9)$, o povo (S1 89,18; 148,14), Davi (Sl 89,25; 132,17), a casa de Israel (Ez 29,21), a filha de Sião (Mq 4,13) e até o adversário (Lm 2,17). Ao contrário, porém, Deus também pode promover ou permitir o "corte", o "despedaçamento" ou o rebaixamento da "fronte" de alguém: ver os perversos

${ }^{15}$ RIEDE, P., "Doch Du erhöhtest wie einem Wildstier mein Horn”, p. 213.

${ }^{16}$ KOENEN, K., “... denn wie der Mensch jedes Tier nennt, so soll es heissen” (Gn 2,19), p. 540.

${ }^{17}$ Ver a imagem encontrada na fortaleza do rei assírio Salmanassar III (859-824 a. C.) em Nimrud, publicada em MALLOWAN, M.; HERRMANN, G., Furniture from SW.7 Fort Shalmaneser, p. 68, e reproduzida em KEEL, O., Jahwes Entgegnung na Ijob, p. 77.

${ }^{18}$ RIEDE, P., "Doch frage die Tiere, sie werden dich lehren", p. 3.

${ }^{19}$ Em Hab 3,4 se pode entender que "chifres" - em vez de "raios" - "estão a partir da mão" de Deus: FABRY, H.-J.; Habakuk/Obadja, p. 278.302. 
(S1 75,11), Moab (Jr 48,25), as nações (Zc 2,4), Jó (Jó 16,15) e Israel (Lm 2,3). No mais, além de o Senhor, como "eternamente elevado" (v. 9a), "elevar a fronte" de seu fiel, ele também pode ordenar aos "perversos" que "não elevem sua fronte" (S1 75,15.16). Quer dizer, a imagem do chifre ou da fronte traz consigo uma dupla conotação. De acordo com a situação, prevê-se a elevação ou o rebaixamento dele ou dela.

Semelhantemente funciona o simile do bovino selvagem. Por mais forte que este animal seja, Deus exerce seu domínio sobre ele (Jó 39,9-10). Assim, junto às nações, a "espada do Senhor" pode fazer "os bovinos selvagens caírem" (Is 34,6-7). Ou imagina-se que "o Senhor faz saltar o Sarion como a cria de bovinos selvagens" (S1 29,6), ou que ele precisa "salvar dos chifres de bovinos selvagens" quem grita por ele (S1 22,22). Em todos esses casos, o animal tão imponente representa uma força caótica capaz de ameaçar o ser humano em sua sobrevivência. Em outros momentos, por sua vez, o mesmo bovino selvagem e seu chifre servem como uma imagem positiva. No caso, Balaão descreve o povo do êxodo como tendo "eminências de um bovino selvagem" (Nm 23,22; 24,8). E Moisés abençoa os israelitas afirmando que "os chifres de José são chifres de um bovino selvagem" (Dt 33,17). Nesse segundo sentido, também o orante no S1 92 afirma que o Senhor teria "elevado a fronte dele como" o chifre de "um bovino selvagem" (v. 11a).

\section{Como a tamareira}

Uma terceira imagem no Sl 92, outra vez introduzida pela proposição

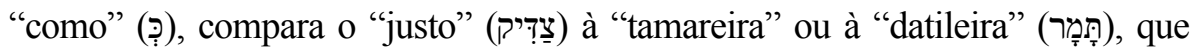
é uma "palmeira" (v. 11a). Trata-se de uma das árvores frutiferas mais antigas, sendo que ela, comprovadamente, já foi cultivada no Egito e na Mesopotâmia desde 5000 a.C. A tamareira atinge uma altura de dez a trinta metros. No extremo do caule, forma-se um tufo com até vinte folhas pinadas de dois a três metros. Entre os seus trinta e cem anos, a árvore produz, anualmente, até cem quilogramas de tâmaras, bagos carnudos de dois a sete centímetros com amido e um porcentual alto de açúcar. Além da produção desse alimento precioso, a tamareira oferece sua madeira como lenha e material de construção, suas folhas para a confecção de tapetes, cestos e outros utensílios, assim como suas fibras que, misturadas com pelos de animais, servem para fazer cordas e lonas. ${ }^{20}$

\footnotetext{
${ }^{20}$ Ver, em vista das informações aqui dadas, RIEDE, P., Palme; SCHÜTTE, I. M., Dattelpalme; ZOHARY, M., Pflanzen der Bibel, p. 60-61.
} 
O nome hebraico do vegetal lenhoso - ver a tamareira (רฺָָָָ) em Ex 15,27; Lv 23,40; Nm 33,9; Sl 92,13; Ct 7,8.9; J1 1,12; Ne 8,15, e com outra vocalização (רֶุת) em Jz 4,5; Jr 10,5 - também existe como nome próprio

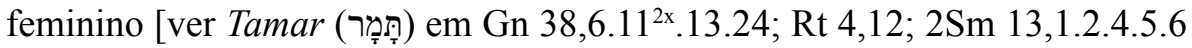
.7.8.10²x.19.20.22.32; 14,$27 ; 1 \mathrm{Cr} 2,4 ; 3,9$ ] e como nome de local [ver Jericó como "cidade das tamareiras" (עִיר הַתְּמָרִרים) em Dt 34,3; Jz 1,16; 3,13; $2 \mathrm{Cr}$ 28,15, ou "Tamar" (תָָָּ )em 1Rs 9,18; Ez 47,19; 48,28]. ${ }^{21}$ Além disso, prevêse o uso de "ramos" ou "folhas de tamareiras" para a festa das cabanas (Lv 23,40; $\mathrm{Ne} 8,15) .^{22}$

Quais, por sua vez, são as prováveis conotações simbólicas da árvore em questão, quando o orante no S1 92 afirma que o "justo florescerá como a tamareira" (v. 13a)? De um lado, é possível que tal árvore represente o

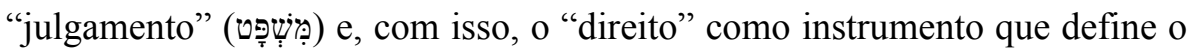
que é justo, sendo que, segundo a tradição, a juíza e profetiza Débora julgava os filhos de Israel "sentada debaixo de uma tamareira" (Jz 4,5). De outro lado, a tamareira espelha com aquilo que ela produz ora a bênção divina, ora o ser humano como quem, por meio de seu comportamento justo, contribui para que exista longevidade e uma produção abundante de bens favorável à sobrevivência de todos. Afinal, cabe ao justo o destino de ser "como uma árvore plantada junto a canais de água, que dá o fruto dela a seu tempo e cuja folhagem não murcha" (S1 1,3). ${ }^{23}$ Tal árvore, certamente, é bem representada por uma tamareira.

\section{Como um cedro}

A quarta imagem no S1 92, mais uma vez introduzida pela proposição

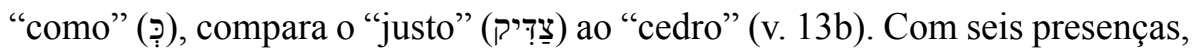
o "cedro" (ארז) é a árvore mais mencionada no livro dos Salmos (S1 29,52x; $80,11 ; 92,13 ; 104,16 ; 148,9)$. Nos demais escritos da Bíblia Hebraica, tal vegetal lenhoso recebe outras sessenta e sete menções.

\footnotetext{
${ }^{21}$ No que se refere a Jr 10,5, talvez se trate de uma "coluna semelhante à palmeira como trabalho de tornearia em madeira ou metal" (DIETRICH, W.; ARNET, S., Konzise und aktualisierte Ausgabe des Hebräischen und Aramäischen Lexikons zum Alten Testament, p. 661), sendo que essa, comumente, é compreendida como "espantalho".

22 Existe ainda o substantivo a ser compreendido como "ornamento de palmeira" ou "orna-

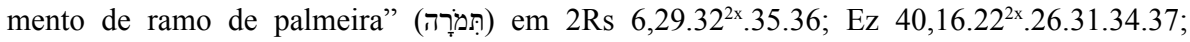
$41,18^{2 \times} \cdot 19^{2 x} \cdot 20.25 .26 ; 2 \mathrm{Cr} 3,5$.

${ }^{23}$ GRENZER, M., Caminhos de justos e perversos (S1 1), p. 16-17.
} 
O cedro existia, sobretudo, no Líbano e na Cilícia, mas não em Israel, por crescer em regiões montanhosas, sobre solos rochosos. Com sua altura de trinta a cinquenta metros e com um diâmetro de tronco de até dois metros, o cedro fornece madeira preciosa de construção, sobretudo por sua resistência. No mundo antigo, as diversas nações a importavam para construir navios (Ez 27,5), templos, palácios e móveis $\left(2 \mathrm{Sm} 5,11 ; 7,2.7\right.$; 1 Rs $5,20.22 .24 ; 6,9.10 .15 .16 .18^{2 x} .20 .36$; 7,2.3.7.11.12; 9,11; Jr 22,14; Ct 1,17; 8,9; Esd 3,7; 1Cr 14,1; 17,1.6; 22,42x; 2Cr 2,2.7), e até ídolos (Is 44,14). Nesse sentido, o cedro se tornou expressão de riqueza (1Rs 10,27; Jr 22,15; 2Cr 1,15; 9,27). Impressiona também como o cedro pode atingir uma idade de até mil anos. ${ }^{24}$ No mais, a madeira do cedro oferece óleos essenciais, com efeitos antissépticos, bactericidas, diuréticos, expectorantes, fungicidas e inseticidas. ${ }^{25}$ Além disso, conforme as leis de culto no Pentateuco, "a madeira do cedro e/ou as lascas dela eram importantes para ritos de santificação e purificação ( $\operatorname{Lv} 14,4.6 .49 .51 .52$; $\mathrm{Nm} \mathrm{19,6)"}{ }^{26}$ Em vista disso, compreende-se também que o cedro era objeto de estudo botânico (1Rs 5,13).

Contudo, tendo em vista a altura e a matéria-prima tão preciosa oferecida por essa árvore, o cedro ganha diversas conotações simbólicas, representando a grandeza, a majestade, o poder e/ou a realeza $(\mathrm{Nm} 24,6 ; \mathrm{Jz} 9,15 ; 2 \mathrm{Rs} 14,9$; 19,23; Is 14,8; 37,24; Ez 31,3.8; Am 2,9; Zc 11,1.2; Jó 40,17; Ct 5,15; $2 \mathrm{Cr}$ 25,18). Em contrapartida, justamente por essa sua representatividade, os cedros podem tornar-se alvos da ação do Senhor, Deus de Israel, como quem combate orgulho, soberba e/ou altivez (Is 2,13; 9,9; Jr 22,7.23). Mais ainda, exige-se do cedro que represente ou testemunhe a ação favorável de Deus a seu povo humilde (Is 41,19; Ez 17,3.22.23).

O que, por sua vez, caracteriza a presença do cedro nos Salmos? Destacase, de forma repetida, o poder que Deus tem sobre essa árvore majestosa. $\mathrm{O}$ Senhor, pois, tem como "destroçar os cedros do Líbano" (S1 29,52x). Mais ainda, ao agir com Israel, os "galhos" dessa sua videira, arrancada por ele do Egito e plantada em terras novas, ganham a tarefa de até "cobrirem os cedros" existentes na mesma região, sendo que estes últimos, como "cedros de Deus", também lhe pertencem (S1 80,11). Aliás, o Senhor, Deus de Israel, é contemplado como quem "plantou os cedros do Líbano" e os sacia com a

${ }^{24}$ ZOHARY, M., Pflanzen der Bibel, p. 104-105; ASSMANN, C., Libanon-Zeder, p. 124-125; RIEDE, P., Zeder, p. 1-7.

${ }^{25}$ ASSMANN, C., Libanon-Zeder, p. 125; DUKE, J. A., Duke's Handbook of Medicinal Plants of the Bible, p. 84.

${ }^{26}$ RIEDE, P., Zeder, p. 2. 
chuva que oferece $(\mathrm{S} 1$ 104,16). Por isso, junto à natureza inteira, cabe também aos "cedros" a tarefa de "louvarem o Senhor" (S1 148,9).

No S1 92, por sua vez, "o justo" é meditado como quem "crescerá como um cedro no Líbano" (v. 13b). De um lado, cabem-lhe, portanto, altura, majestade, grandeza, poder, realeza e longevidade, a fim de servir a projetos de construção e à saúde física e espiritual dos seres humanos. De outro lado, por mais que se destaque e possa ter um bom futuro, o justo, como cedro, deve estar consciente do poder de Deus sobre ele e da primazia de Israel.

\section{Conclusão}

Quem reza no Salmo 92 contempla repetidamente fauna e flora. Surgem, com isso, quatro comparações que acolhem vegetais herbáceos (v. 8a) e lenhosos (v. 13a.b), assim como um animal selvagem (v. 11a). Além disso, o orante observa que, em meio à natureza, existem os processos de "florescer" (v. 8a.13a.14b), "brotar" (v. 8b), "crescer" (v. 13b), "plantar" (v. 14a), "prosperar" (v. 15a), "ser seivoso" (v. 15b) e "ser exuberante" (v. 11b.15b). Mais ainda, assim como existem "elevações" (v. 11a), também há a possibilidade de ocorrerem "supressões" (v. 8c).

Com esse olhar atento e pormenorizado para a natureza, nasce a ideia de que fauna e flora guardem uma lição de vida e/ou uma sabedoria própria para o ser humano, sendo que esta, constantemente, culmina na reflexão sobre Deus. Nesse sentido, é possível dizer que as orações bíblicas presentes nos Salmos, em determinados momentos, promovem uma ecoteologia e/ou uma ecoespiritualidade. ${ }^{27}$ Quer dizer, os Salmos convidam seus ouvintes-leitores a acolher e a respeitar a natureza, inclusive o espaço onde prevalece a vida selvagem como "lugar de contemplação e isolação da vida no dia a dia", a fim de reorganizar seu pensamento e reencontrar-se com a ordem prevista por Deus para este mundo. ${ }^{28}$ Consequentemente, a destruição de fauna e flora apenas iria eliminar um importante lugar de encontro com Deus. ${ }^{29}$

\footnotetext{
${ }^{27}$ Em 2016, Espíndola e Lodoño apresentaram elementos iniciais de uma leitura ecológica dos Salmos (ESPÍNDOLA, L. G.; LODOÑO, A., Perspectiva a partir da Bíblia, p. 146-148).

${ }^{28}$ DYK, P. van, Eco-Theology, p. 848. Numa pesquisa recentemente publicada, foi possível mostrar que também o legislador israelita não estava alheio às questões ambientais e, com isso, ecoteológicas e/ou ecoespirituais (GRENZER, M.; GROSS, F., Leis deuteronômicas favoráveis à preservação de fauna e flora).

${ }^{29}$ A presente pesquisa sobre o Salmo 92 foi aceita para ser discutida, em julho de 2020, no International Meeting da SBL (Society of Biblical Literature).
} 


\section{Referências bibliográficas}

ASSMANN, C. Libanon-Zeder. In: HÄUSL, M. (Org.). Vom Garten Eden bis zu Salomos Weinberg: Pflanzen in der Bibel. Stuttgart: Katholisches Bibelwerk, 2018. p. 124-125.

BAUMGART, N. C. Die Umkehr des Schöpfergottes: zu Komposition und religionsgeschichtlichem Hintergrund Von Gen 5-9. Freiburg: Herder, 1999.

COMMITTEE ON TRANSLATIONS OD THE UNITED BIBLE SOCIETIES. Fauna and Flora of the Bible. London: United Bible Society, 1980.

DEYSEL, L. C. F. Animal names and categorisation in the Hebrew Bible:

a textual e cognitive approach. Pretoria, 2017. 333p. Doctoral thesis. Faculty of Humanities, University of Pretoria.

DIETRICH, W.; ARNET, S. Konzise und aktualisierte Ausgabe des Hebräischen und Aramäischen Lexikons zum Alten Testament (KAHAL). Leiden: Brill, 2013.

DYK, P. van. Eco-Theology: In and out of the Wilderness. Old Testament Essays, v.30, n.3, p. 833-849, sep./oct. 2017.

DUKE, J. A. Duke's Handbook of Medicinal Plants of the Bible. Boca Raton: CRC Press, 2008.

ESPÍNDOLA, L. G. G.; LONDOÑO, A. Perspectiva a partir da Bíblia. In: MURAD, A. (Org.). Ecoteologia: um mosaico. São Paulo: Paulus, 2016. p. 146-148.

FABRY, H.-J. Habakuk/Obadja. Freiburg: Herder, 2018.

GRENZER, M. Caminhos de justos e perversos (S1 1). In: FERNANDES, L. A.; GRENZER, M. Dança, ó terra! Interpretando Salmos. São Paulo: Paulinas, 2013. p. 9-23.

GRENZER, M. Pastoreio e hospitalidade do Senhor (S1 23). In: FERNANDES, L. A.; GRENZER, M. Dança, ó terra! Interpretando Salmos. São Paulo: Paulinas, 2013. p. 69-89.

GRENZER, M.; BREY, P. Águia ou abutre? (Ex 19,4). Revista de Cultura Teológica, v.25, n.90, p. 347-360, jul./dez. 2017.

GRENZER, M.; GROSS, F. Leis deuteronômicas favoráveis à preservação de fauna e flora. Pistis \& Praxis, v.11, n.3, p. 778-791, set./dez. 2019. 
HÄUSL, M. (Org.). Vom Garten Eden bis zu Salomos Weinberg: Pflanzen in der Bibel. Stuttgart: Katholisches Bibelwerk, 2018.

KEEL, O. Jahwes Entgegnung na Ijob: Eine Deutung von Ijob 38-41 vor dem Hintergrund der zeitgenössischen Bildkunst. Göttingen: Vandenhoeck \& Ruprecht, 1978.

KOENEN, K. “... denn wie der Mensch jedes Tier nennt, so soll es heissen” (Gn 2,19): Zur Bezeichnung von Rindern im Alten Testament. Biblica, v.75, n.4, p. 539-546, out./dez. 1994.

MAIBERGER, P. עָשָׁב 'ése $\underline{b}$. In: BOTTERWECK. G. J.; RINGGREN, H.; FABRY, H.-J. Theological Dictionary of the Old Testament. Grand Rapids, Michigan: Eerdmans, 2015. p. 383-386. v. XI.

MALLOWAN, M. E. L.; HERRMANN, G. Furniture from SW.7 Fort Shalmaneser: Ivories from Nimrud (1949-1963). London: British School of Archaeology in Iraq, 1974. v.III.

MUSSELMAN, L. J. A Dictionary of Bible Plants. Cambridge: University Press, 2012.

RIEDE, P. "Doch du erhöhtest wie einem Wildstier mein Horn": Zur Metaphorik in Ps 92,11. In: HECKE, P. van; LABAHN, A. Metaphors in the Psalms. Leuven: Peeters, 2010. p. 209-216.

RIEDE, P. "Doch frage die Tiere, sie werden dich lehren": Tiere als Vorbilder und "Lehrer" im Alten Testament. In: RIEDE, P. Im Spiegel der Tiere: Studien zum Verhältnis von Mensch und Tier im alten Israel. Freiburg: Universitätsverlag; Göttingen: Vandenhoeck \& Ruprecht, 2002. p. 1-28.

RIEDE, P. Palme. In: Das Wissenschaftliche Bibellexikon im Internet. 2018. Disponível em: <http://www.wibilex.de>. Acesso em: 19 jan. 2020.

RIEDE, P. Zeder. In: Das Wissenschaftliche Bibellexikon im Internet. 2017. Disponível em: <http://www.wibilex.de>. Acesso em: 30 out. 2019.

SARNA, N. M. The Psalm for the Sabbath Day (Ps 92). Journal of Biblical Literature, v.81, n.2, p. 155-168, apr./Jun. 1962.

SCHÜTTE, I. M. Dattelpalme. In: HÄUSL, M. (Org.). Vom Garten Eden bis zu Salomos Weinberg: Pflanzen in der Bibel. Stuttgart: Katholisches Bibelwerk, 2018. p. 77-78.

SEYBOLD, K. Poetik der Psalmen. Stuttgart: Kohlhammer, 2003. 
STICHER, C. "Die Gottlosen gedeihen wie Gras": $\mathrm{Zu}$ einigen Pflanzenmetaphern in den Psalmen. Eine kanonische Lektüre. In: HECKE, P. van; LABAHN, A. Metaphors in the Psalms. Leuven: Peeters, 2010. p. 209-216.

TAL, A. All the Trees of the Forest: Israel's Woodlands from the Bible to the Present. New Haven \& London: Yale University Press, 2013.

TUCKER, W. D. The Ordered World of Palm 92. Old Testament Essays, v.32, n.2, p. 358-377, may/aug. 2019.

ZENGER, E. Psalm 92. In: ZENGER, E.; HOSSFELD, F.-L. Psalmen 51100. Freiburg: Herder, 2000. p. 636.

ZOHARY, M. Pflanzen der Bibel. 2.ed. Stuttgart: Calwer, 1986.

Matthias Grenzer Doutor em Teologia pela Faculdade de Filosofia e Teologia St. Georgen em Frankfurt Docente na Faculdade de Teologia da Pontifícia Universidade

Católica de São Paulo São Paulo / SP - Brasil E-mail: mgrenzer@pucsp.br

Recebido em: 27/01/2020

Aprovado em: 17/03/2020 